\title{
Pharmacology Versus Convenience: A Benefit/Risk Analysis of Regular Maintenance Versus Infrequent or As-Needed Inhaled Corticosteroid Use in Mild Asthma
}

Peter Daley-Yates · Bhumika Aggarwal · Zrinka Lulic · Sourabh Fulmali •

Alvaro A. Cruz · Dave Singh

Received: September 8, 2021 / Accepted: October 26, 2021 / Published online: December 7, 2021

(C) The Author(s) 2021

\section{ABSTRACT}

Introduction: This study compared the bronchoprotective and benefit/risk profiles of various inhaled corticosteroid (ICS) dosing regimens in mild asthma.

Methods: A pharmacokinetic/pharmacodynamic model was developed and validated describing the relationship between ICS dose and time-course for airway bronchoprotection, [provocative concentration of adenosine monophosphate (AMP) causing $\geq 20 \%$ decline

P. Daley-Yates $(\bowtie)$

Clinical Pharmacology and Experimental Medicine,

GlaxoSmithKline Plc., Brentford, London, UK

e-mail: peter.t.daley-yates@gsk.com

B. Aggarwal

Respiratory, Global Classic and Established

Products, GlaxoSmithKline, Singapore 139234,

Singapore

Z. Lulic

Global Classic and Established Products,

GlaxoSmithKline, Brentford, London, UK

S. Fulmali

Respiratory, Global Classic and Established

Products, GlaxoSmithKline, Mumbai, India

A. A. Cruz

Faculty of Medicine, Federal University of Bahia and

Fundacao ProAR, Salvador, Brazil

D. Singh

University of Manchester and Manchester

University NHS Foundation Trust, Manchester, UK in forced expiratory volume in $1 \mathrm{~s}\left(\mathrm{FEV}_{1}\right)$ (AMP $\left.\mathrm{PC}_{20}\right)$ ], for fluticasone furoate $(\mathrm{FF})$, fluticasone propionate (FP) and budesonide (BUD). For regular ICS maintenance therapy (100\% and $50 \%$ adherence) and infrequent or as-needed use (dosing 3-4 times per week), treatment effectiveness was expressed as percent time during 28 days when bronchoprotection exceeded either the threshold for a treatment-related bronchoprotective effect (AMP $\quad \mathrm{PC}_{20} \geq 0.25$ doubling dose) or the threshold for a clinically significant bronchoprotective effect (AMP $\mathrm{PC}_{20} \geq 1.0$ doubling dose). This value was divided by the total ICS dose administered expressed in prednisolone equivalents to give a therapeutic index (TI).

Results: The model-predicted time course of ICS-induced bronchoprotection with regular daily maintenance dosing and $100 \%$ adherence showed that all ICS at the highest recommended doses for mild asthma exceeded the threshold for clinically significant bronchoprotective effect for all or most of the 28-day dosing period, mean (90\% CI); 100\% (96.1-100), 99.9\% $(8.0-100)$ and $100 \%(58.2-100)$ with TI values of 16.9, 6.6 and 5.4 for FF $100 \mu \mathrm{g}$ OD, FP $200 \mu \mathrm{g}$ BID and BUD $200 \mu \mathrm{g}$ BID, respectively. For simulated poor adherence (50\%) to regular daily maintenance therapy, corresponding mean (90\% CI) values were; $75.7 \%$ (39.4-89.1), 52.3\% (0.7-69.2) and 51.3\% (28.6-58.3) with TI values of 25.7, 6.9 and 5.6. For simulated infrequent/as needed use the corresponding values were; 
$77.0 \%$ (37.6-87.0), 25.5\% (0.0-38.0) and 26.2\% (14.3-31.5) with TI values of 26.1, 6.7 and 5.7. For all regimen/scenarios, FF had the most sustained efficacy and favourable TI followed by FP and BUD.

Conclusions: At doses recommended for mild asthma, all ICS regimens provide sustained bronchoprotective efficacy when dosed regularly with high adherence. With poor adherence or use 3-4 times per week (infrequent/as needed), longer-acting ICS molecules will more likely provide sustained protection and a better TI versus shorter duration of action molecules (FF $>$ FP $\geq$ BUD). These data highlight the benefits of using ICS as regular daily maintenance dosing in mild asthma and the potential risks of under-treatment with ICS (which may occur with ICS/formoterol as-needed approach in mild persistent asthma) associated with reduced levels of bronchoprotection.

Keywords: Adherence; AMP challenge; Asthma; Budesonide; Fluticasone furoate; Fluticasone propionate; PK/PD model; Asneeded; Regular dosing

\section{Key Summary Points}

Why carry out this study?

Early intervention with inhaled corticosteroids (ICS) in mild persistent asthma reduces the risk of severe exacerbations and the associated decline in lung function. However, adherence to ICS in mild asthma is often poor.

The Global Initiative for Asthma recommends ICS/formoterol as-needed as an alternative treatment option to regular daily low-dose ICS plus as-needed shortacting beta agonist (SABA), but this approach has not been universally accepted or endorsed.
This study developed and applied a pharmacokinetic/pharmacodynamic model to compare the bronchoprotective and benefit/risk profiles of various ICS dosing regimens and clinical scenarios of adherence with fluticasone furoate (FF), fluticasone propionate (FP) and budesonide (BUD), in mild asthma.

What was learned from the study?

At doses recommended for mild asthma, all ICS can achieve good bronchoprotective efficacy with low systemic activity when dosed regularly with high adherence. For clinical scenarios that reflect poor adherence or infrequent dosing regimens of 3-4 times per week (as-needed), longer-acting ICS molecules (FF and to some extent FP) achieve better efficacy and overall benefit/ risk ratios compared with shorter duration of action molecules (BUD), due to prolonged duration of airway GR occupancy and low systemic activity.

These data support regular daily maintenance dosing with ICS in patients with mild persistent asthma, reinforce the importance of encouraging better adherence with regular daily maintenance dosing regimens to ensure sustained levels of bronchoprotective efficacy and highlight the potential risks of undertreatment with ICS.

\section{INTRODUCTION}

Inhaled corticosteroids (ICS) have a pivotal role in the management of asthma across all levels of disease severity [1, 2]. In mild persistent asthma, early intervention with regular daily ICS has shown benefits in terms of achieving asthma control, reducing the risk of a severe exacerbation, as well as reducing the decline in lung function associated with an exacerbation $[3,4]$. ICS also play an important role in preventing asthma deaths $[5,6]$. However, adherence to ICS is often poor with reported mean 
levels of adherence ranging from 22 to $70 \%$ [7-13], and mild asthma is particularly associated with poor adherence [10]. The Global Initiative for Asthma (GINA) options for management of mild asthma include regular daily low-dose ICS plus as-needed (PRN) shortacting beta agonist (SABA) or ICS/formoterol asneeded without regular ICS use [1]. While the key randomized controlled trials evaluating ICS/formoterol as-needed reported similar annual rates of exacerbations between regular daily ICS maintenance therapy and ICS/formoterol as-needed dosing regimens, better control of asthma symptoms with ICS regular daily maintenance therapy versus ICS/formoterol as-needed was also demonstrated [14-16]. Despite the GINA report's novel strategy, there is limited regulatory authority acceptance globally of ICS/formoterol as-needed and this approach has not been adopted universally by national treatment guidelines, which continue to endorse the use of regular daily low-dose ICS plus SABA as-needed as the preferred treatment option in patients with mild persistent asthma [2, 17-19].

When ICS were first developed as a regular daily maintenance therapy for patients with asthma, dosing regimens and frequency of dosing were led by pharmacology-based evidence and first-generation ICS molecules were typically dosed 3-4 times per day, later superseded by molecules that were effective with twice-daily dosing, including budesonide (BUD) and fluticasone propionate (FP) [20-24]. The more recently introduced fluticasone furoate (FF), which has greater glucocorticoid receptor (GR) binding affinity and longer lung retention [25], now allows once-daily dosing [26]. Studies of the pharmacokinetic (PK)/pharmacodynamic (PD) properties of ICS and underlying PK/PD dose-response relationships for duration of effect on airway inflammation and bronchial hyperresponsiveness (BHR), have demonstrated that duration of activity can vary widely between ICS molecules and that this is related to lung retention and the duration of airway glucocorticoid receptor occupancy [25, 27-30]. Although ICS dosing recommendations acknowledge that some molecules are potentially longer acting, with posologies varying from four-times daily to once daily, the clinical effect of different dosing regimens with ICS molecules that have different pharmacological properties, including duration of action, has not been fully explored.

The extent and retention of the ICS molecules in the airway is determined by the dose delivered to the lung, its solubility and dissolution and absorption rate from the lung [25]. Post-dose, the lung concentration of the ICS declines in line with the absorption rate from the lung, and this concentration, together with the GR dissociation constant, determines the degree of GR occupancy and how long it is maintained [25]. These parameters provide a theoretical basis for ICS molecules differing in their duration of action. Against this background pharmacological evidence, recommendations for the use of short-acting ICS molecules, such as beclomethasone dipropionate and BUD in ICS/formoterol as-needed dosing regimens, appear to be largely based on patient convenience while accepting that adherence to regular daily maintenance therapy in patients with asthma is poor [1].

Patients with mild asthma tend to have infrequent symptoms and near-normal lung function [1], while elevated exhaled nitric oxide levels are not always present. The presence of BHR is a hallmark of asthma and may be used as a criterion to confirm a diagnosis of asthma. A significant association between asthma symptom control and change in BHR to adenosine- $5^{\prime}$ monophosphate (AMP) after ICS treatment has been shown [31, 32]. The measurement of BHR is therefore a marker of treatment efficacy in asthma, in spite of its potential for high individual variability [33]. In mild asthma, treatment driven by clinical symptoms, including the ICS/formoterol as-needed approach, could allow underlying inflammation and BHR to persist and potentially worsen [34-36]. Indeed, evidence on the long-term effects of the ICS/ Formoterol as-needed approach, beyond 52 weeks, in controlling underlying inflammation, BHR and airway remodelling are lacking [37-39].

We hypothesised that the extent of GR occupancy correlates with the extent of bronchoprotection. To test this hypothesis for 
different ICS, previously published dose response data for ICS on BHR in asthma [40], and the known ICS PK/PD parameters $[25,27-30]$, were used to construct a mathematical model. The model was then used to (1) study the relationship between GR occupancy and BHR using published data from clinical trials and (2) simulate the differences in BHR with different ICS dosing regimens (regular daily maintenance dosing vs. infrequent or asneeded use, which is typically 3-4 doses per week) and clinical scenarios of adherence for regular daily maintenance therapy $(100 \%$ and $50 \%$ adherence).

\section{METHODS}

\section{Model Development}

\section{Estimating GR Occupancy in the Lung}

The first step of model development was to describe the relationship between the dose and the concentration-time profile for the fraction of the administered drug dose that is available to bind to airway GR. The lung concentrations for BUD, FP and FF were derived using published values for the dose fraction available to the lung and the lung absorption rate [25]. A key assumption of the model was that the amount of ICS absorbed from the lung into the systemic circulation was equal to the bioavailable fraction in the lung during the dose interval and uniformly distributed throughout lung tissue, and hence potentially available for GR binding $[29,30]$. However, in practice, the extent of GR occupancy achieved in the target cells will vary for each ICS molecule, driven not only by their GR binding affinities but also by their physicochemical properties. The physicochemical properties that most likely influence drug availability for GR binding are solubility, lipophilicity and permeability, since they determine dissolution and partitioning into target cells and tissues within the airway. Although these factors are independently quantifiable in vitro, it is not known how these factors interact in vivo within the airways. It has been reported that differences in permeability observed for steroids have a weak inverse correlation with lipophilicity (ClogP) [41]. Although other structural features of the molecule may also influence permeability, it is expected that BUD with lower lipophilicity may have higher permeability compared to the more lipophilic molecules like FP and FF. Therefore, these factors were taken into account by including a tissue-partitioning parameter, $\mathrm{CP}_{\mathrm{T}}$, in the model (see below) which was estimated in the model relative to BUD.

The lung concentration-time profiles generated in this way together with the ICS GR dissociation constants were used to estimate the time-course for the extent and duration of GR occupancy in the lung.

\section{Defining the Relationship Between GR Occupancy and Bronchoprotection}

In step 2, a mathematical model was used to describe the relationship between airway GR occupancy and its impact on bronchoprotection [defined as a provocative concentration of AMP resulting in a decline of $\geq 20 \%$ in forced expiratory volume in $\left.1 \mathrm{~s}\left(\mathrm{FEV}_{1}\right), \mathrm{AMP} \mathrm{PC}_{20}\right]$. For the various ICS dose regimens used in the model building dataset [40], the ICS dose (D), dose fraction deposited in the lung ( $F=$ dose fraction absorbed from the lung) and the lung volume $\left(V_{\mathrm{L}}, 1000 \mathrm{~mL}\right)$ were used to estimate the post-dose concentration of drug in the lung $\left.\mathrm{C}_{\mathrm{LO}}=D \cdot F / V_{\mathrm{L}}\right)$. From the $\mathrm{C}_{\mathrm{LO}}$ and the absorption rate from the lung $k=(\ln 2 /$ lung elimination half-life) the lung concentration time profile $\left(C_{\mathrm{L}}=\mathrm{CP}_{\mathrm{T}} \cdot \mathrm{CL}_{0} \cdot \mathrm{e}^{-\mathrm{kt}}\right)$ was estimated. The tissuepartitioning parameter, $\mathrm{CP}_{\mathrm{T}}$, was assigned a fixed value of 1.0 for BUD and estimated as 0.18 for FP and $0.48 \mathrm{FF}$. These values are in agreement with BUD having the lowest lipophilicity and highest permeability and with FF having greater permeability, uptake and retention in respiratory tissue than FP $[42,43]$. From this, the lung $\% \mathrm{GR}_{\mathrm{L}}$ occupancy time profile was estimated $\left(\% \mathrm{GR}_{\mathrm{L}}=100 \times C_{\mathrm{L}} /\left(C_{\mathrm{L}}+K_{\mathrm{D}}\right)\right]$ where $K_{\mathrm{D}}=\mathrm{GR}$ dissociation constant.

\section{Clinical Data}

The clinical data used for model development were derived from a recently completed clinical trial investigating a wide range of doses of three 
ICS molecules (FF, FP and BUD) [40]. In brief, 54 subjects with asthma [baseline mean percent predicted $\mathrm{FEV}_{1}$ of $85.5 \%$ (SD 12.9\%)] were randomized to one or two of four treatment periods. Subjects were screened for AMP responsiveness, i.e. AMP $\quad \mathrm{PC}_{20}<80 \mathrm{mg} / \mathrm{mL}$ using a wide range of dilutions $(0.04,0.08,0.16$, $0.32,0.63,1.25,2.5,5.0,10.0,20.0,40.0,80.0$, 160.0 and $320.0 \mathrm{mg} / \mathrm{mL}$ ) and had a mean baseline value $\mathrm{AMP} \mathrm{PC}_{20}$ of $15.15 \mathrm{mg} / \mathrm{mL}$ (SD $16.3 \mathrm{mg} / \mathrm{mL}$ ). Each study period comprised five dose escalations ( $\mu \mathrm{g} /$ day) of 7 days duration: FF $(25,100,200,400,800)$, FP $(50,200,500,1000$, $2000)$, BUD $(100,400,800,1600,3200)$ or placebo, with a 25- to 42-day washout period between exposures. At the end of each escalation, $12 \mathrm{~h}$ post-dose, the AMP $\mathrm{PC}_{20}$ was assessed. Mean data for the AMP $\mathrm{PC}_{20}[\mathrm{mg} / \mathrm{mL}$ and doubling dose (DD)] were used together with mean PK data from other published sources [25], to enable a PK/PD analysis.

This article is not based on any new studies with human participants or animals performed by any of the authors. The study data used in this study were derived from completed clinical trial (Protocol study 203,162; NCT02991859). ${ }^{40}$ The original study was approved by local ethics committees for the participating institutions [Ethikkommission des Landes Berlin, Berlin, Germany (reference number 17/0432-EK 10), and North West-GM South, NHS Health Research Authority, Manchester, UK (reference number 16/NW/0781)].

\section{Model Validation}

The PK/PD model was validated by comparing the observed data values (AMP doubling dose versus placebo) with the corresponding model predicted values for four studies, that were not part of the model building dataset [44-47]. These data comprised a range of ICS doses, single and repeat dose regimens and AMP challenge assessment conducted at various times post-dose (summarised in Table 1).

\section{Model Application}

The model was used to estimate the extent of airways GR occupancy, and thereby the corresponding extent of bronchoprotection, at any time post-dose for different ICS dosing regimens (regular daily maintenance dosing vs. infrequent or as-needed use) and clinical scenarios of adherence for regular daily maintenance therapy (100\% and 50\% adherence). Infrequent was defined as ICS use of 3-4 doses per week based on the reported average use of BUD/formoterol as-needed dosing regimen in randomized trials in mild asthma [14-16]. The ICS dose regimens tested were FF (100 $\mu \mathrm{g} / \mathrm{OD}$ and $200 \mu \mathrm{g} / \mathrm{OD})$, FP (100 $\mu \mathrm{g} / \mathrm{bid}, 200 \mu \mathrm{g} / \mathrm{bid}$ and $250 \mu \mathrm{g} / \mathrm{bid})$ and BUD $(100 \mu \mathrm{g} / \mathrm{bid}$ and $200 \mu \mathrm{g} / \mathrm{bid})$.

For these dosing regimens and clinical scenarios, model estimates for the duration of the bronchoprotective effect (\% of time, hours) during a month of therapy (28 days) were compared using two thresholds. The first threshold was defined as an $\mathrm{AMP} \mathrm{PC}_{20} \geq 16 \mathrm{mg} /$ $\mathrm{mL}$ ( $\geq 0.25$ DD difference from placebo), this approximates to the average baseline (pre-ICS treatment) $\mathrm{AMP} \mathrm{PC}_{20}$ screening value for the patient population in the model building dataset [40]; hence, below this value, we assumed no treatment-related bronchoprotective effect. The second threshold was defined as an $\mathrm{AMP} \mathrm{PC}_{20}$ of $\geq 27 \mathrm{mg} / \mathrm{mL}$; this corresponds to $\mathrm{a} \geq 1 \mathrm{DD}$ difference from placebo and is considered to be the threshold for a clinically significant bronchoprotective effect [40, 44-49]. Between these two thresholds, although treatment effects are predicted, they were assumed to be sub-optimal in terms of achieving a clinically significant bronchoprotection. We have compared the model outputs with these two threshold levels to estimate the time during treatment when these two treatment effects are exceeded.

For the purposes of the simulations, high adherence to regular daily maintenance therapy (100\% adherence) was defined as all the prescribed doses for BUD and FP (twice daily every $12 \mathrm{~h}$ ) or FF (once daily every $24 \mathrm{~h}$ ) taken during a 28-day period. Poor adherence to regular daily maintenance therapy $(50 \%$ adherence $)$ was defined as half the prescribed doses for BUD, FP or FF taken during a 28-day period. Where 50\% 
Table 1 Details of studies used for PK/PD model validation

\begin{tabular}{|c|c|c|c|c|}
\hline Study & $\begin{array}{l}\text { Number of subjects/ } \\
\text { study design }\end{array}$ & $\begin{array}{l}\text { ICS } \\
\text { molecule }\end{array}$ & ICS doses and dosing frequency & AMP measurements \\
\hline \multicolumn{5}{|l|}{ Ketchell et al. ${ }^{a}$} \\
\hline Study 1 & $\begin{array}{l}\text { 12/placebo-controlled } \\
\text { crossover }\end{array}$ & $\mathrm{FP}$ & $\begin{array}{l}100 \mu \mathrm{g}, 250 \mu \mathrm{g} \text { or } 1000 \mu \mathrm{g} \text { single } \\
\text { dose }\end{array}$ & $\begin{array}{l}\text { BHR to AMP measured } 2 \mathrm{~h} \\
\text { post-dose }\end{array}$ \\
\hline Study 2 & $\begin{array}{l}\text { 12/placebo-controlled } \\
\text { crossover }\end{array}$ & $\mathrm{FP}$ & $\begin{array}{l}100 \mu \mathrm{g}, 250 \mu \mathrm{g} \text { or } 1000 \mu \mathrm{g} \text { single } \\
\text { dose }\end{array}$ & $\begin{array}{l}\text { BHR to AMP measured } 2 \mathrm{~h} \\
\text { post-dose }\end{array}$ \\
\hline Luijk et al. ${ }^{b}$ & $\begin{array}{l}\text { 13/ placebo-controlled, } \\
\text { four-way crossover }\end{array}$ & $\mathrm{FP}$ & $1000 \mu \mathrm{g}$ single dose & $\begin{array}{l}\text { BHR to AMP measured at } \\
2,14 \text { or } 26 \mathrm{~h} \text { post-dose }\end{array}$ \\
\hline Phillips et al. ${ }^{\mathrm{c}}$ & $21 /$ three-way crossover & BUD & 100,400 and $1600 \mu \mathrm{g} /$ repeat dose & $\begin{array}{l}\text { BHR to AMP measured } 6 \mathrm{~h} \\
\text { post-dose }\end{array}$ \\
\hline $\begin{array}{l}\text { GSK study } \\
\text { SIG } 103337^{\mathrm{d}}\end{array}$ & $\begin{array}{l}\text { 45/incomplete-block, } \\
\text { 4-period crossover } \\
\text { study }\end{array}$ & $\mathrm{FP}$ & $\begin{array}{l}50 \mu \mathrm{g}, 100 \mu \mathrm{g}, 250 \mu \mathrm{g}, 500 \mu \mathrm{g}, \\
1000 \mu \mathrm{g} \text { or } 2000 \mu \mathrm{g} \text { repeat dose }\end{array}$ & $\begin{array}{l}\text { BHR to AMP measured } 2 \mathrm{~h} \\
\text { post-dose }\end{array}$ \\
\hline
\end{tabular}

${ }^{\mathrm{a}}$ Reference [44] ${ }^{\mathrm{b}}$ Reference [45] ${ }^{\mathrm{c}}$ Reference $[46]{ }^{\mathrm{d}}$ Reference [47] ${ }^{\mathrm{e}}$ Average time post-dose

$A M P$ adenosine-5'-monoposphate, $B H R$ bronchial hyperresponsiveness, $B U D$ budesonide, $F P$ fluticasone propionate

adherence was assumed, this was implemented by randomly assigning a 50\% probability that a dose would be taken for each of the 56 planned dose events that occur in a 28-day period of prescribed bid dosing for BUD and FP or the 28 once-daily dosing events for FF. The same randomly generated sequence of missed and taken doses was applied to all the 50\% adherence simulations. For simulation of as-needed approach, 3-4 inhalations per week were assumed. This was implemented for each 7-day period by alternating between either 3 or 4 inhalations taken randomly during each 7-day period for 28 days. The same randomly generated sequence of taken doses was applied to all the as-needed simulations.

\section{Comparison of Benefit/Risk Profiles for ICS Dosing Regimens}

To compare the relative risk of different ICS regimens and clinical scenarios of adherence, the total ICS dose administered was converted into a prednisolone equivalent dose, representing the systemic exposure for total ICS dose in terms of the dose of orally administered prednisolone that would be required to produce the equivalent systemic exposure and extent of cortisol suppression, as previously described [25]. This calculation first involves converting the ICS dose into a plasma AUC before converting this into the equivalent prednisolone AUC and dose using the bioavailability, clearance and relative GR binding affinity of each molecule.

An index of the benefit/risk ratio or therapeutic index (TI) for each of the ICS regimens and adherence scenarios was calculated as the percentage of time (hours) during a 28-day period when there was a treatment-related bronchoprotection effect (AMP $\geq 0.25 \mathrm{DD}$ or $\mathrm{AMP} \geq 1.0 \mathrm{DD}$ ) divided by the total ICS dose administered in the same period, expressed as a prednisolone equivalent dose.

\section{Statistical Analysis}

Original source data preparation, modelling, summary statistics and data presentations were performed using SAS software (v.9.2 or higher; Cary, NC, USA). Other calculations, simulation and plots were produced in Microsoft Excel. 


\section{RESULTS}

\section{Relationship Between Airway GR Occupancy and Bronchoprotection}

The relationship between ICS-induced airway bronchoprotection, defined as a change in AMP $\mathrm{PC}_{20}$, and airway GR occupancy was well described by exponential or log-linear function: AMP $\mathrm{PC}_{20}=101.72 .\left(100-\mathrm{GR}_{\mathrm{L}} \%\right)^{-0.56}$ with a high degree of correlation $\left(r^{2}=0.981\right)$ (Fig. 1). The small deviation seen between the data and model prediction line at the highest dose of FF (Fig. 1, log-linear inset plot) was expected because some subjects may have had underestimated AMP $\mathrm{PC}_{20}$ values as they did not achieve a $20 \%$ fall in $\mathrm{FEV}_{1}$ at the highest concentration of AMP tested $(320.0 \mathrm{mg} / \mathrm{mL})$.

\section{Model Validation}

Both the visual inspection and the correlation coefficient between observed data values (AMP

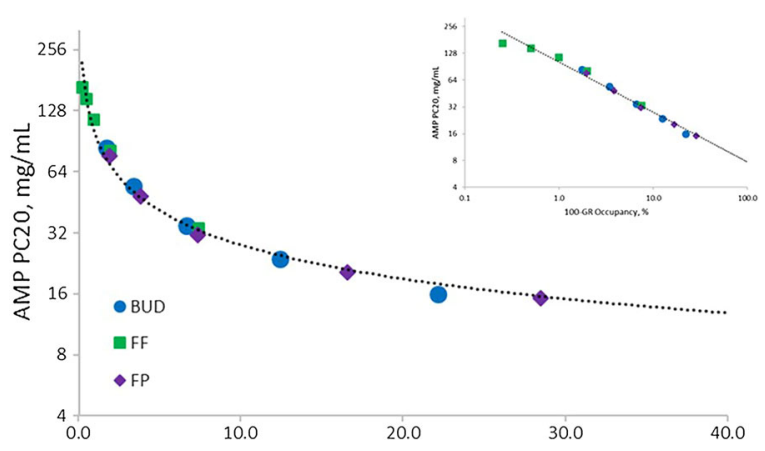

Fig. 1 Relationship between estimated glucocorticoid receptor occupancy in the lung $\left(\mathrm{GR}_{\mathrm{L}}\right)$ and bronchoprotection. Glucocorticoid receptor occupancy plotted as $100-\mathrm{GR}_{\mathrm{L}}$ after dosing with FF $(25,100,200,400,800 \mu \mathrm{g} /$ OD), FP $(50 \mu \mathrm{g} / \mathrm{OD}, 100,250,500,1000 \mu \mathrm{g} / \mathrm{bid}), \mathrm{BUD}$ $(100 \mu \mathrm{g} / \mathrm{OD}, 200,400,800,1600 \mu \mathrm{g} / \mathrm{bid})$ and bronchoprotection assessed as the reduction in airway hyperresponsiveness (AMP $\mathrm{PC}_{20}$ ) assessed $12 \mathrm{~h}$ post-dose after 7 days dosing (data from [40]). The dotted line shows the non-linear correlation where AMP $\mathrm{PC}_{20}=101.72(100-$ $\left.\mathrm{GR}_{\mathrm{L}} \%\right)^{-0.56}$ with a correlation coefficient of $r^{2}=0.981$. Inset the same data as a log-linear plot. AMP adenosine-5'monophosphate, BUD budesonide, FF fluticasone furoate, FP fluticasone propionate doubling dose versus placebo) and the corresponding model predicted values from four other studies showed good agreement $\left(r^{2}=0.836\right)$ and supported the validity of the PK/PD model (Fig. 2).

\section{Model Application}

The model-predicted time course of ICS-induced airway bronchoprotection during 28 days dosing with the regular daily maintenance dosing regimen and the $100 \%$ adherence scenario showed that all ICS provided a bronchoprotective effect during the dosing period, with $\geq 0.25$ and $\geq 1$ DD bronchoprotection for all or most of the 28-day period (Table 2). Figure 3 illustrates these data for each ICS at their highest recommended doses for mild asthma (FF $100 \mu \mathrm{g}$ OD, FP $200 \mu \mathrm{g}$ BID and BUD $200 \mu \mathrm{g}$

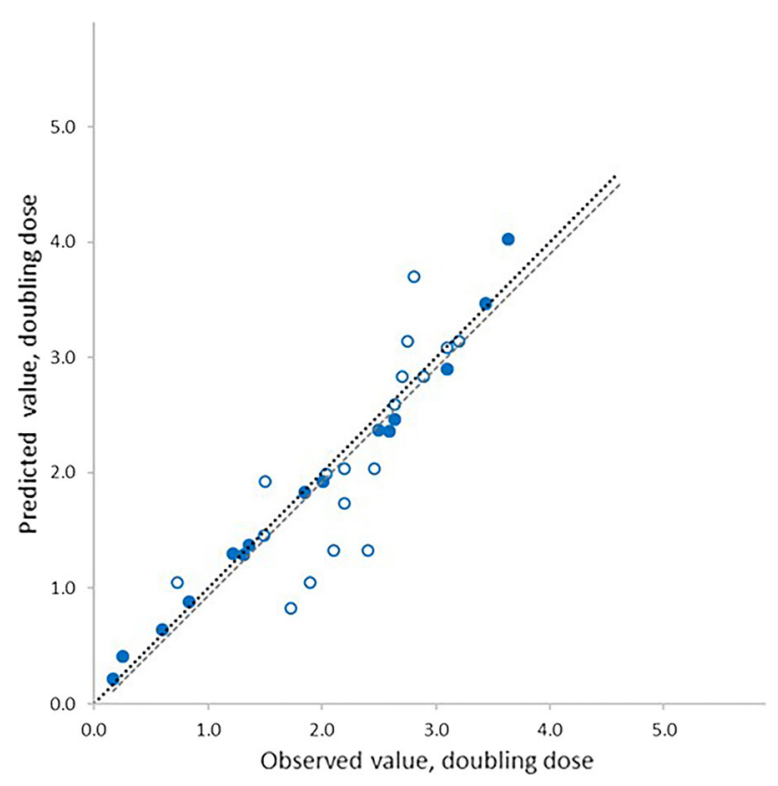

Fig. 2 Model validation. The model was validated by comparing the observed data values (AMP doubling dose versus placebo) with the corresponding model predicted values for four studies that were not part of the model building dataset (Table 1) shown as open circles. These data comprised a wide range of ICS doses, single and repeat doses regimens and AMP challenge assessment conducted at various times between 2 and $26 \mathrm{~h}$ post-dose. The data from the model building dataset [40] are shown as solid circles. The line of identity (slope $=1$ ) and linear regression $\left(r^{2}=0.836\right) \ldots \ldots$ are also shown 


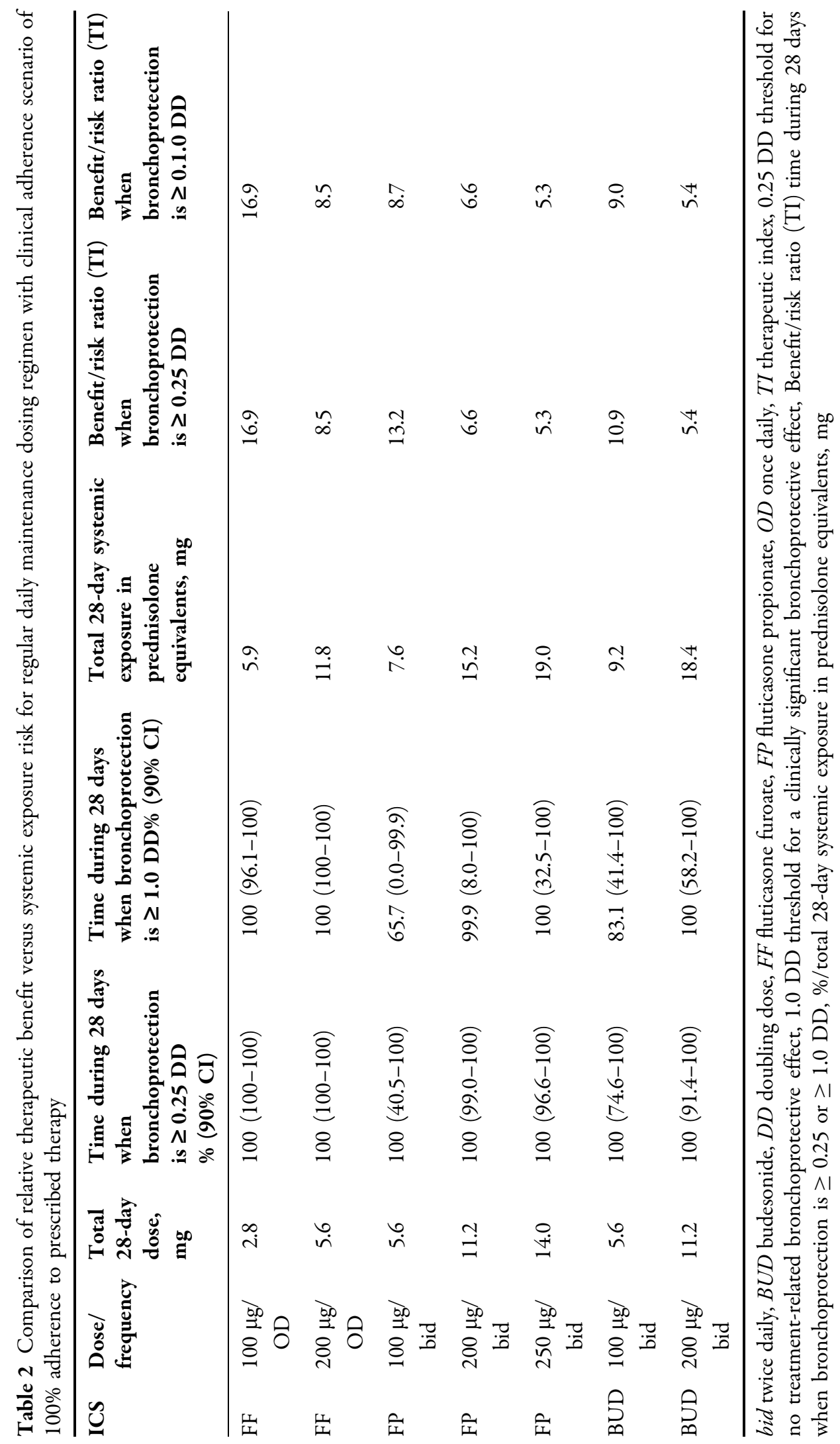



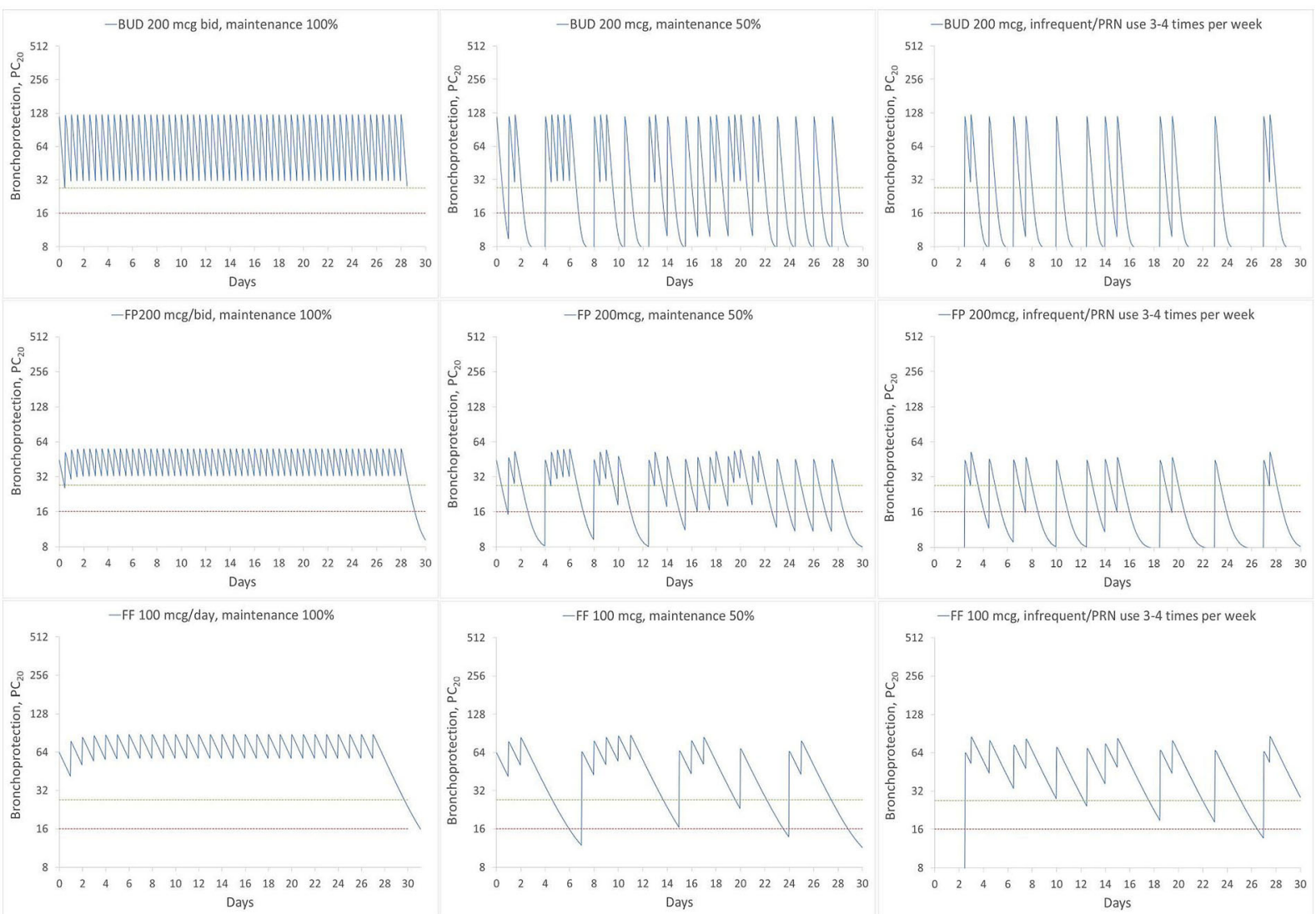

Fig. 3 Model predicted time course of ICS induced airway bronchoprotection during 28 days dosing. Dosing was with BUD $200 \mu \mathrm{g}$ bid, FP $200 \mu \mathrm{g}$ bid and FF $100 \mu \mathrm{g}$ OD with: regular daily maintenance dosing regimen with adherence scenario of $100 \%$ adherence (column 1), regular daily maintenance dosing regimen with adherence scenario of $50 \%$ adherence (column 2), ICS dosing regimen when ICS used infrequently or PRN 3-4 times per week (column 3). For each ICS molecule, ICS doses represent the highest

BID) for each ICS dosing regimen and adherence scenario, and Fig. 4 illustrates the relative amount of time with bronchoprotection $\geq 0.25$ or $\geq 1$ DD.

For the simulation of a regular daily maintenance dosing regimen and a 50\% adherence scenario, the model predictions showed a range of bronchoprotective effects, with FF providing significantly greater bronchoprotection than BUD (Table 3). Bronchoprotective effects provided by dosing with FP fell between FF and BUD. For the highest recommended dose of each ICS for mild asthma, the lower threshold therapeutic dose for mild asthma. Horizontal dotted lines indicate thresholds for no treatment-related bronchoprotective effect defined as bronchoprotection less than an AMP $\mathrm{PC}_{20}$ of $16 \mathrm{mg} / \mathrm{mL}$ (0.25 doubling doses) and a clinically significant bronchoprotective effect defined as bronchoprotection greater than an AMP $\mathrm{PC}_{20}$ of $27 \mathrm{mg} /$ $\mathrm{mL}$ (1.0 doubling doses). bid twice daily, $B U D$ budesonide, $F F$ fluticasone furoate, $F P$ fluticasone propionate

for bronchoprotection ( $\geq 0.25 \mathrm{DD}$ ) was exceeded during the 28-day dosing period, with means (90\% CI), for 94.9\% (68.7-100), 78.3\% (39.8-90.5) and $60.6 \%(44.9-70.4)$ of the time for FF, FP and BUD, respectively. The corresponding values for the higher and clinically significant threshold of bronchoprotection $(\geq 1.0$ DD) were $75.7 \% \quad(39.4-89.1), \quad 52.3 \%$ (0.7-69.2) and 51.3\% (28.6-58.3) for FF, FP and BUD, respectively (Figs. 3,4 ).

The simulated predictions for the infrequent ICS dosing regimen (dosing 3-4 times per week) showed that FF provided notably greater 


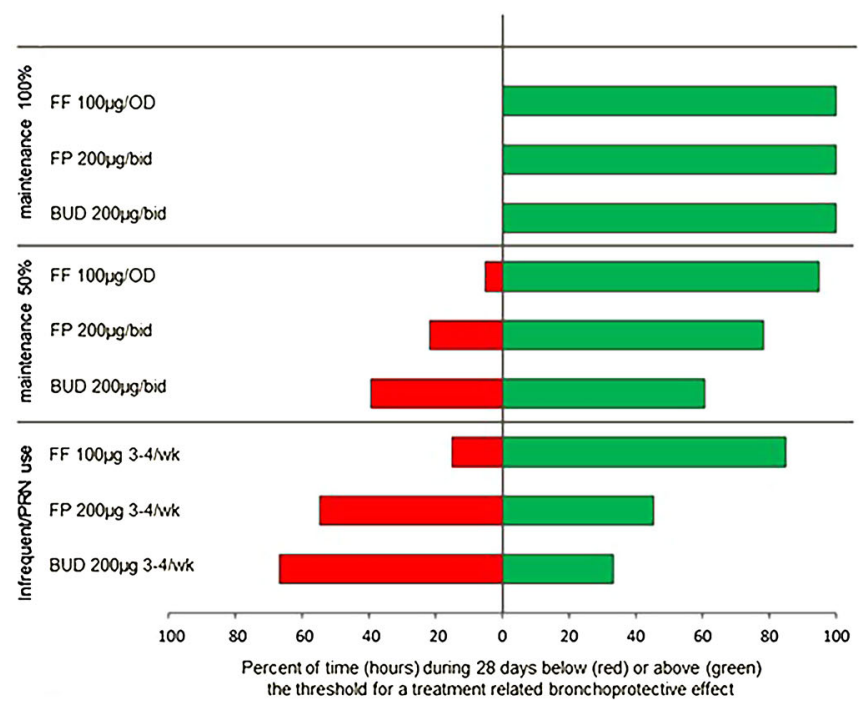

Fig. 4 Percent time (hours) during 28 days above or below the thresholds for bronchoprotection. Thresholds for bronchoprotection were: no treatment-related bronchoprotective effect (left panel), or a clinically significant bronchoprotective effect (right panel) for BUD $200 \mu \mathrm{g}$ bid, FP $200 \mu \mathrm{g}$ bid and FF $100 \mu \mathrm{g}$ OD with: regular daily

bronchoprotection than BUD and FP (Table 4). For the highest recommended dose of each ICS for mild asthma, the lower threshold for bronchoprotection (0.25 DD) was exceeded during the 28-day dosing period, with means $(90 \% \mathrm{CI})$ for $84.9 \%$ (70.0-91.1), $45.3 \%(17.8-58.0)$ and $33.2 \%(22.4-40.2)$ of the time for FF, FP and BUD, respectively. The corresponding values for the higher threshold of bronchoprotection $(\geq 1.0$ DD) were $77.0 \% \quad(37.6-87.0), 25.5 \%$ (0.0-38.0) and 26.2\% (14.3-31.5) for FF, FP and BUD, respectively (Figs. 3, 4).

For each ICS molecule, total 28-day systemic exposure prednisolone equivalents were highest for the regular daily maintenance ICS regimen and $100 \%$ adherence scenario and lowest for the infrequent ICS dosing regimen, as would be expected, but low systemic exposure and estimated cortisol suppression $<20 \%$ was observed for all ICS even when used with $100 \%$ adherence (Tables 1, 2, 3; Fig. 5). With respect to the benefit/risk ratio (TI), within each ICS dosing regimen and adherence scenario, FF had the highest (most favourable) TI and BUD had the lowest with FP falling between the two

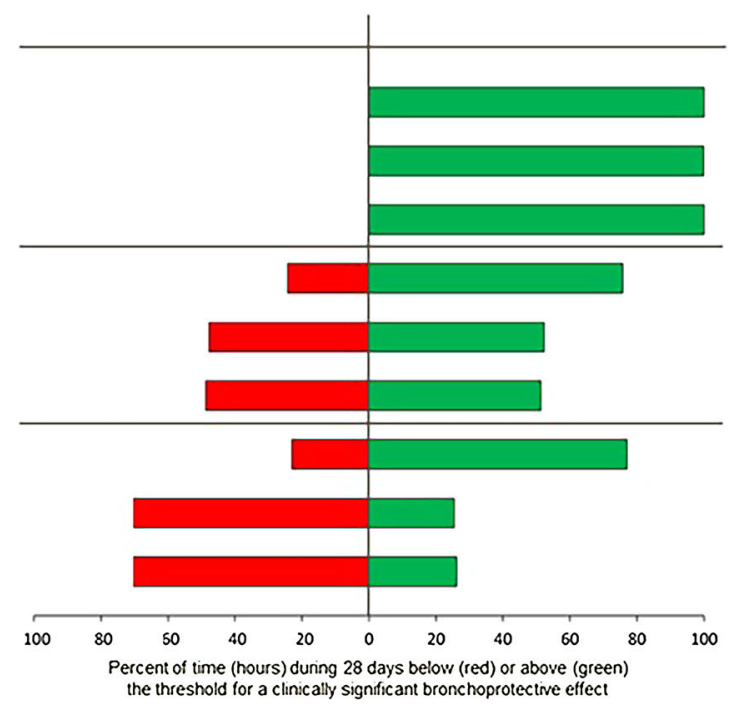

maintenance dosing regimen with adherence scenario of $100 \%$ adherence, regular maintenance daily dosing regimen with adherence scenario of $50 \%$ adherence, infrequent ICS dosing regimen (3-4 times per week). bid twice daily, BUD budesonide, FF fluticasone furoate, FP fluticasone propionate, $O D$ once daily

(Tables 1, 2, 3). For the highest recommended dose of each ICS for mild asthma, and for bronchoprotection exceeding the lower threshold, the TIs for FF, FP and BUD, respectively, were 16.9 , 6.6, 5.4 (regular daily maintenance dosing regimen, $100 \%$ adherence scenario), $32.2,10.3,6.6$ (regular daily maintenance dosing regimen, $50 \%$ adherence scenario) and 28.8, 11.9, 7.2 (dosing 3-4 times per week). The corresponding values for the higher and clinically significant threshold of bronchoprotection for FF, FP and BUD were, respectively, either unchanged at $16.9,6.6,5.4$ (regular daily maintenance dosing regimen, $100 \%$ adherence scenario), or, similar, 25.7, 6.9, 5.6 (regular daily maintenance dosing regimen, 50\% adherence scenario) and 26.1, 6.7, 5.7 (dosing 3-4 times per week) (Fig. 6).

\section{DISCUSSION}

This study used a novel PK/PD model to compare the bronchoprotective effects of different ICS dosing regimens and clinical adherence scenarios, and demonstrated that, with regular 


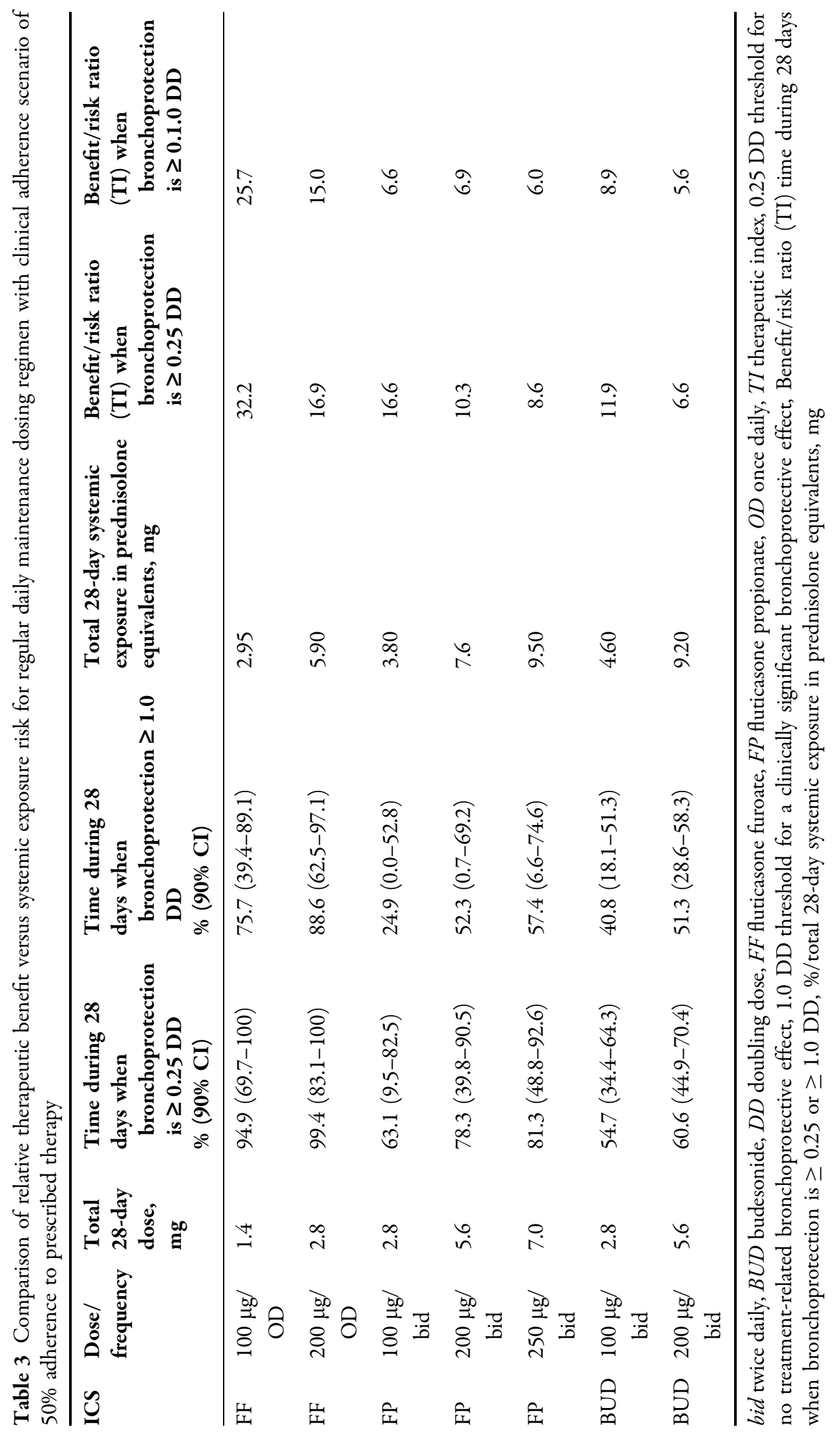




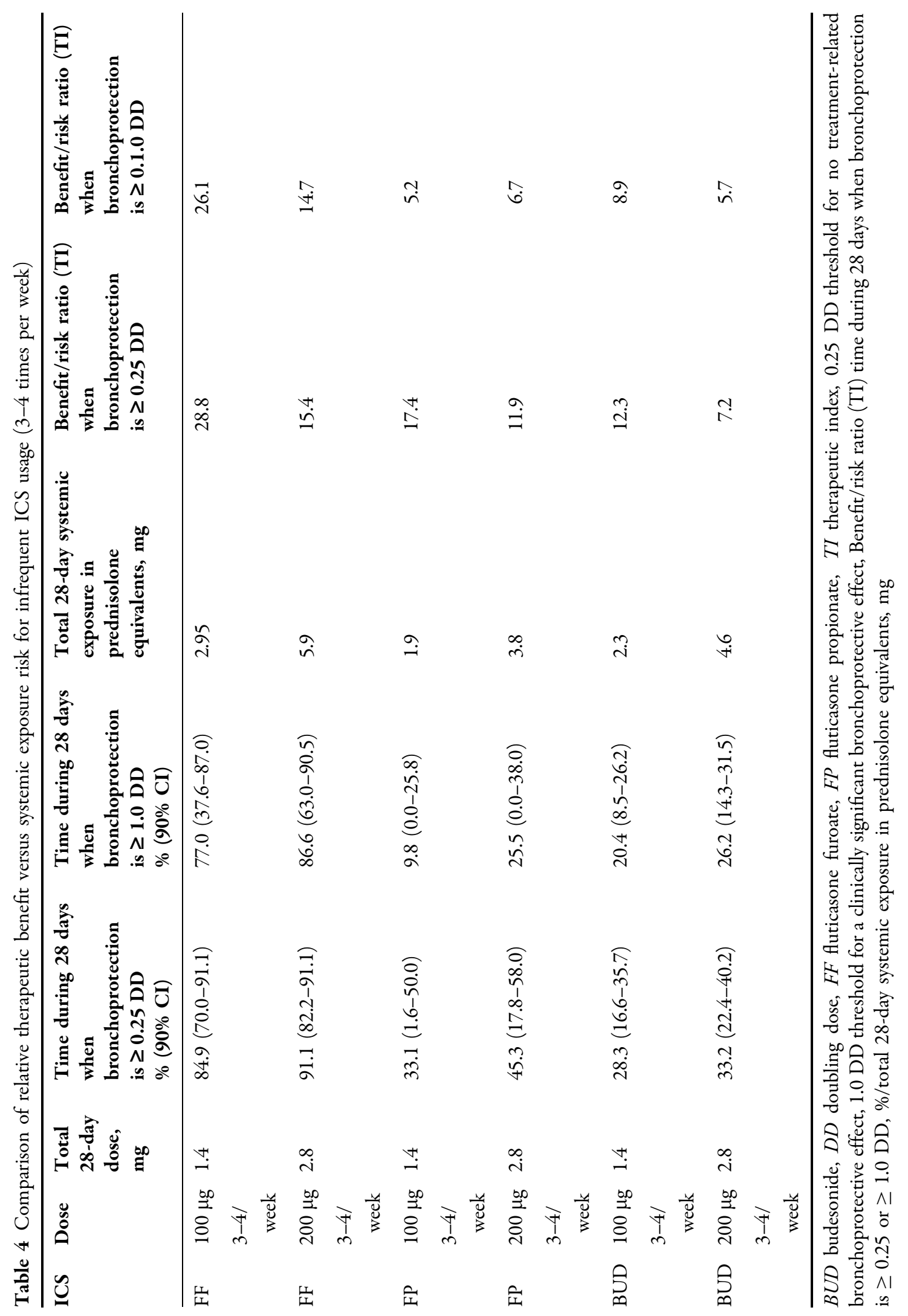




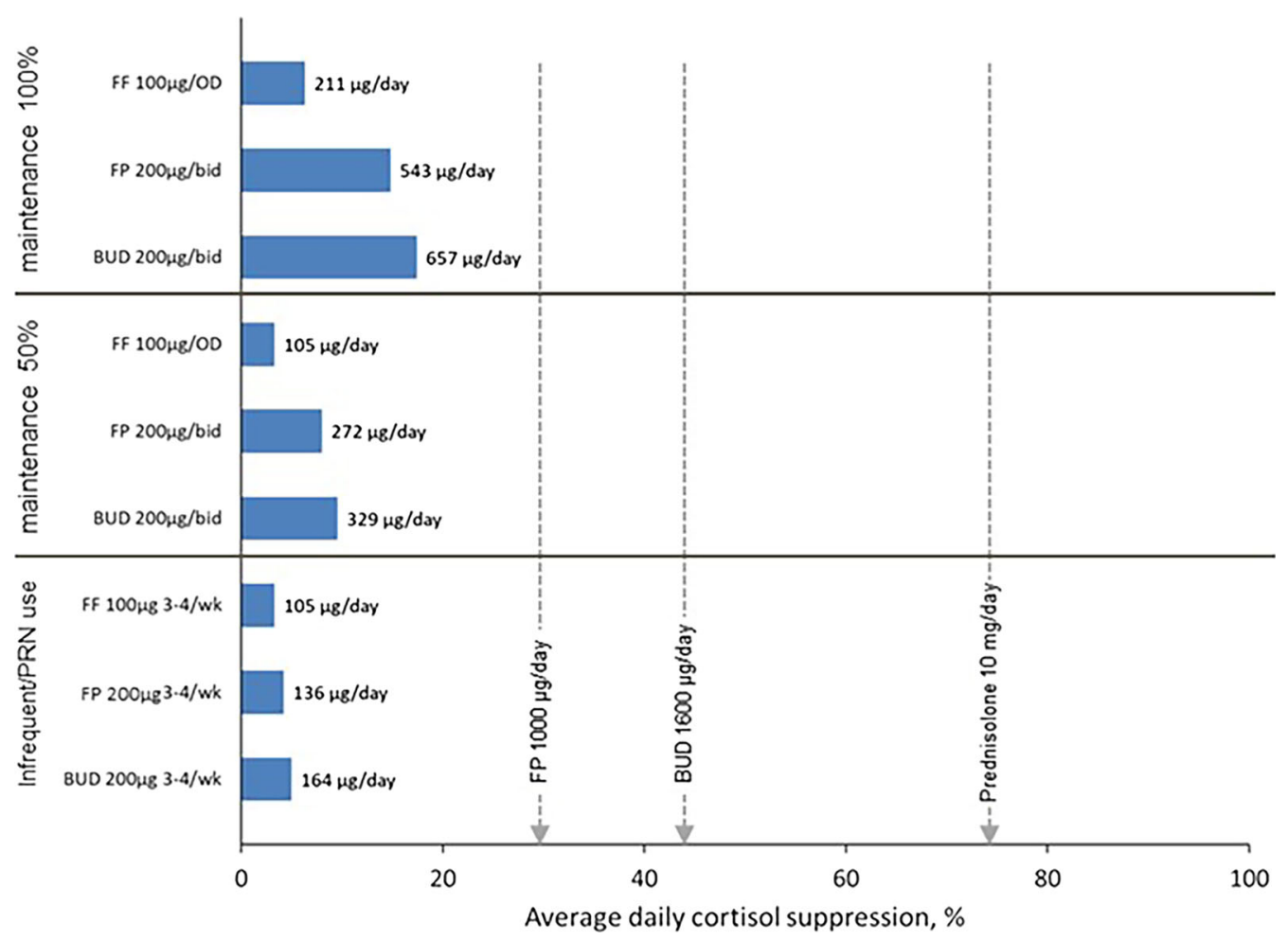

Fig. 5 Average daily prednisolone equivalent dose $(\mu \mathrm{g} /$ day) and cortisol suppression during 28 days dosing. Dosing was with BUD $200 \mu \mathrm{g}$ bid, FP $200 \mu \mathrm{g}$ bid and FF $100 \mu \mathrm{g}$ OD with: regular daily maintenance dosing regimen with adherence scenario of $100 \%$ adherence,

daily dosing and high levels of adherence, all ICS have the potential to provide sustained levels of efficacy, at doses recommended for mild asthma. For the clinical scenario that reflected poor adherence (50\%), reduced levels of bronchoprotection were observed for all ICS molecules at their maximum recommended doses for mild asthma, but FF provided a greater duration of bronchoprotection than BUD, whereas FP was greater or similar to BUD. The results were similar when ICS were dosed 3-4 times per week for the simulation of less frequent use, as typically seen with as-needed use of ICS/formoterol in mild asthma. The benefit/ risk ratio profile or TI was most favourable for FF and least favourable for BUD with FP greater or similar to BUD and suggested that the TI was driven by both the efficacy and the safety component. This is particularly relevant for mild asthma where lower doses of ICS are used regular daily maintenance dosing regimen with adherence scenario of $50 \%$ adherence, infrequent ICS dosing regimen (3-4 times per week). bid twice daily, $B U D$ budesonide, $F F$ fluticasone furoate, $F P$ fluticasone propionate, $O D$ once daily

and hence there is low systemic activity. Indeed, as shown in Fig. 5, the degree of systemic exposure with low-dose ICS regimens appropriate for mild asthma produce low systemic exposure and estimated cortisol suppression $<20 \%$ for all ICS when used with $100 \%$ adherence.

All ICS molecules demonstrated effective bronchoprotection over the whole dosing period under simulations of regular daily maintenance dosing with $100 \%$ adherence. In real life, however, poor adherence with regular daily maintenance therapies is often reported in asthma, with mean levels ranging between 22 and 70\% [7-13]. Poor adherence is a key driver in determining the type of treatment approach in patients with mild asthma with ICS/formoterol as-needed being recommended in cases of poor adherence [1]. To our knowledge, this is the first investigation to analyse differences 

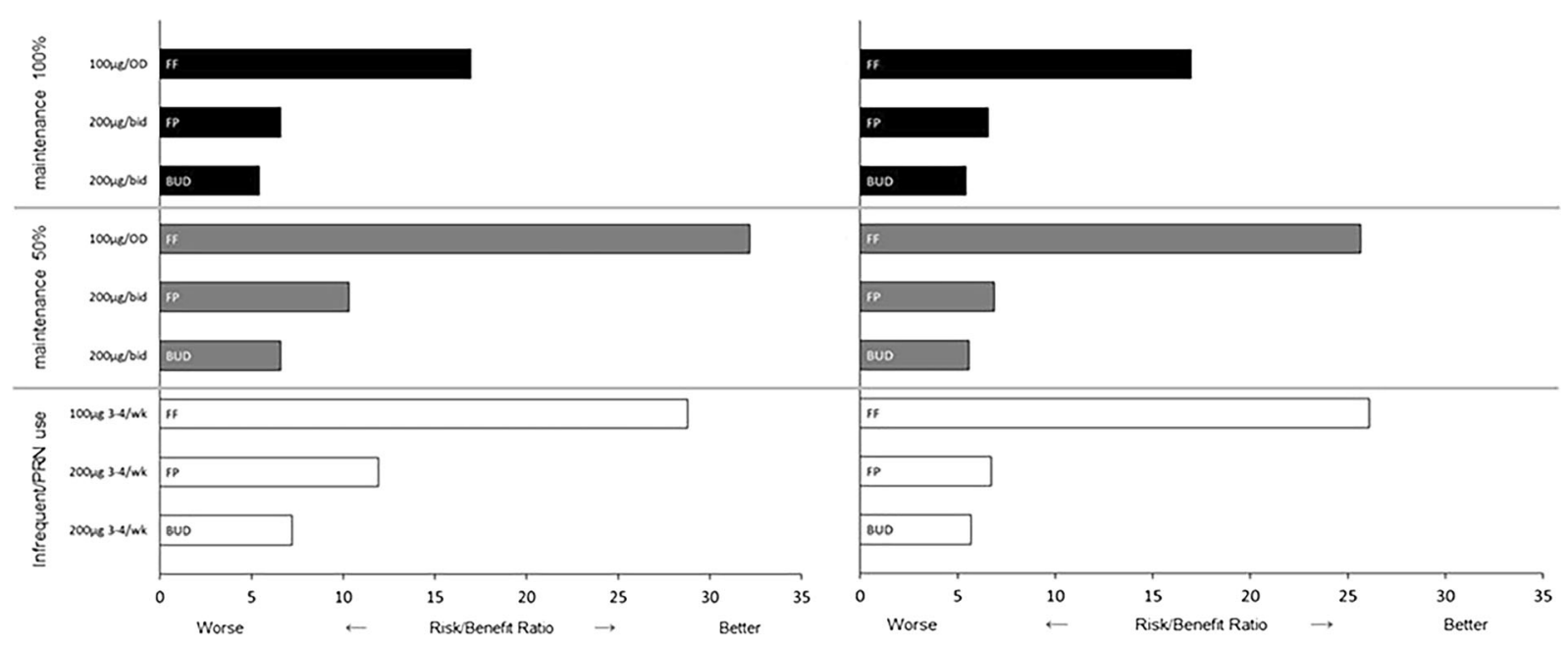

Fig. 6 Risk/benefit ratio (TI). Dosing was with BUD $200 \mu \mathrm{g}$ bid, FP $200 \mu \mathrm{g}$ bid and FF $100 \mu \mathrm{g}$ OD with: regular daily maintenance dosing regimen with adherence scenario of $100 \%$ adherence, regular daily maintenance dosing regimen with adherence scenario of 50\% adherence, infrequent ICS dosing regimen (3-4 times per week). Benefit $/$ risk ratio $=\mathrm{TI}=\%$ time (hours) during 28 days

between ICS molecules with regard to the level of effectiveness with different dosing regimens (regular daily maintenance dosing and dosing 3-4 times per week to simulate an as-needed dosing approach) and scenarios of good and poor adherence. The greatest impact of poor adherence or with an as-needed dosing approach on reducing the duration of bronchoprotection was observed with the shorter duration of action ICS and BUD, whereas longer-acting FF was least impacted by these scenarios, while FP fell between these two. These differences in duration of action are clearly seen after regular dosing, where FF $100 \mu \mathrm{g} /$ day maintained some degree of bronchoprotection for $97 \mathrm{~h}$ post-dose and a clinically significant bronchoprotection for $64 \mathrm{~h}$ post-dose, whereas the corresponding values for BUD $200 \mu \mathrm{g} / \mathrm{bid}$ were $16 \mathrm{~h}$ and $12 \mathrm{~h}$, and for FP $200 \mu \mathrm{g} / \mathrm{bid} 26 \mathrm{~h}$ and $14 \mathrm{~h}$ (Fig. 3, column 1). This can be explained by the pharmacology and physicochemical properties of the ICS, with shorter duration of action molecules like BUD having lower GR affinity but higher tissue permeability, and hence are not retained in lung tissue or on GR receptors for very long [25]. when bronchoprotection is above the threshold for no treatment-related bronchoprotective effect (left panel) or is above the threshold for a clinically significant bronchoprotective effect (right panel), each divided by the total 28-day systemic exposure in prednisolone equivalents, mg. bid twice daily, $B U D$ budesonide, $F F$ fluticasone furoate, $F P$ fluticasone popionate, $O D$ once daily

However, this may result in a higher GR occupancy immediately post-dose (Fig. 3). More lipophilic ICS like FF and, and to some extent FP, have higher GR affinity, slower GR dissociation rate and prolonged tissue retention, hence GR occupancy and bronchoprotection is maintained for much longer post-dose, as observed for FF even with low doses and less frequent dosing. Therefore, the main difference between ICS molecules is not the extent of GR occupancy maintained during regular dosing but the duration of GR occupancy in the airways that can be maintained post-dose, as the latter corresponds to the duration of the bronchoprotective effect in the airways [40].

Our investigation highlights the risks of under-treatment with ICS, which can occur with ICS/formoterol as-needed regimens in mild persistent asthma, as recommended by GINA [1]. As asthma is a chronic inflammatory disease, periods with sub-optimal bronchoprotection may lead to increased inflammation, risk of exacerbation, and in the long term a greater risk of declining lung function and airway remodelling [31, 33-36, 50]. Indeed, our findings are relevant to the current GINA 
treatment recommendations in mild asthma [1]. GINA no longer makes a distinction between "intermittent" and "mild persistent asthma" since these historical definitions were based on an untested assumption that patients with symptoms twice a week or less would not benefit from an ICS. However, GINA now concludes that such patients with mild asthma are at risk of severe exacerbations and that this risk is reduced by ICS containing treatment. Hence, for these patients, the GINA-preferred treatment option is no longer SABA only but use of an ICScontaining treatment, specifically as needed BUD/formoterol. However, this position overlooks the point that severe exacerbations are rare in these patients ( $\leq 1$ /year) [1], but., by comparison, symptoms are evidently not rare, because the recommendation is for patients to take their medication when symptoms appear and on average this occurs 3-4 times per week [14-16]. This situation highlights that as-needed BUD/formoterol can result in under-treatment with an ICS, and, as found in our investigation, could result in sub-optimal control of underlying airway hyperresponsiveness and, as seen in clinical studies, poor control of airway inflammation and frequent symptomdriven use of medication as described above [14-16].

In the randomised, 1-year BUD/formoterol as-needed studies, BUD/formoterol as-needed versus regular BUD plus SABA as-needed resulted in a similar reduction in risk of severe exacerbations but less symptom control and number of well-controlled asthma weeks [14-16]. One real-life study indicated that BUD/formoterol as-needed versus regular dosing was more effective at preventing severe exacerbations and offered similar levels of symptom control, but was less effective in terms of anti-inflammatory effects (as measured by fractional exhaled nitric oxide) [51]. Boushey et al. also reported that symptom-guided short courses of corticosteroids (inhaled BUD or oral prednisolone) were significantly less effective than regular daily maintenance therapy in treating measures of inflammation (bronchial reactivity, the percentage of eosinophils in sputum and exhaled nitric oxide levels) [52]. The results from this PK/PD modelling study are consistent with these findings on anti-inflammatory effects in clinical trials. As-needed ICS/ formoterol dosing strategies have lower ICS exposure versus regular daily maintenance therapy [14-16], but this perceived benefit is small based on our benefit-risk profile analysis, and therefore it needs to be critically evaluated in the context that adequate suppression of underlying inflammation should be the principal aim of ICS therapy. The ICS/ Formoterol PRN studies state that the patients used this, on average, 3-4 times per week [14-16]. The results from the current analysis imply that undertreatment with ICS (as seen with ICS/formoterol as-needed approach in mild persistent) asthma could potentially result in chronic underlying inflammation and poorer clinical outcomes. In light of the results shown in clinical studies, it has been emphasised that more data on the long-term anti-inflammatory effects of ICS/formoterol as-needed in mild asthma are required [37-39], and the results from our study support these recommendations.

Reasons for non-adherence with regular daily ICS maintenance therapies are multifactorial, many of which can be overcome through a greater understanding of a patient's perceptions about their asthma; by effective education on the disease, medications and device; through shared decision-making; and by the monitoring of patient adherence and provision of feedback $[9,12]$. Currently, data on adherence with ICS/formoterol as-needed dosing strategies are not available. However, this strategy does rely on patients accurately perceiving their level of symptoms and asthma control to take their medication. Under-perception of symptoms is common in patients with asthma [53], which may lead to delays or absence in taking appropriate medication and the potential risk of ongoing inflammation and severe exacerbations.

In this study, FF was shown to have the highest (most favourable) TI and BUD was shown to have the lowest, with FP falling between the two. The TI of a molecule is related to both safety and efficacy. In mild asthma, the maximum recommended doses of BUD, FP and FF all result in low systemic exposure and cortisol suppression of less than $15 \%$, which is 
within the normal daily variability of cortisol fluctuations [40], therefore arguing for as-needed use in mild asthma based on better safety is not convincing, whereas under-treatment with ICS that potentially results in the need to use oral corticosteroids is likely to be far less safe in the long term. Steroid phobia, where it exists, may be perpetuated by the 'as-needed' narrative because it, misleadingly, suggests that low-dose ICS are not safe. The data from the current study endorses the safety of the recommended ICS doses for mild asthma and show that the efficacy component is the most important driver in determining TI. From a clinical perspective, these data suggest that, for the usual recommended dose of $\mathrm{BUD} /$ formoterol as-needed for mild asthma (200/6 $\mu \mathrm{g})$ [1], patients are at risk of effectively having no bronchoprotective cover for $67 \%$ of the time and may lack clinically significant bronchoprotection for $74 \%$ of the time. This implies that patients who are already poorly adherent to treatment could effectively be even less adherent with an asneeded dosing regimen, and thus even more vulnerable to having a suboptimal bronchoprotective cover.

A strength of this study is in the rigorous approach used to develop the PK/PD model. The model was well validated, shown by the comparison of model-predicted with observed data generated in previous studies not included in the model building (Fig. 2). In addition, data generated with the model in this study are also consistent with reports that regular daily lowdose ICS (i.e. the dose range recommended for mild asthma) can produce most of the efficacy with little more being achieved with higher doses $[54,55]$. We used AMP $\mathrm{PC}_{20}$ to measure bronchoprotective effects, an advantage being that it is a non-invasive tool to assess response to treatment [56]. AMP is an indirect challenge agent that is highly specific, more closely correlates with acute changes in airway inflammation than methacholine and histamine challenge, significantly correlates with allergic sensitization and symptoms, and is more responsive to investigating short-term responses to anti-inflammatory medication [32, 57-61].

A limitation of this PK/PD modelling approach was in the assumptions made about
GR binding, as these have not been directly validated by measurements in the lung in man; however, data in animals with lung GR binding measurements appear to agree with these assumptions [62]. In modelling the bronchoprotective effects, we only estimated the effect of the ICS that arises via its anti-inflammatory mechanism of action. Short- and longacting $\beta_{2}$ agonist bronchodilators do not possess anti-inflammatory activity but they can have a bronchoprotective effect, which can be assessed via direct challenge agents such as methacholine that act on airway smooth muscle. However, their effect on bronchoprotection via AMP is likely to be minor and short lived. Hence, when BUD/formoterol is administered, the major contribution to bronchoprotection will be from the ICS component [63]. Only one random use sequence for the clinical scenario of poor adherence was generated, although in theory an infinite number could be generated. Hence, the $50 \%$ adherence simulation provides only one example of sub-optimal adherence but nevertheless is expected to be typical of the average usage pattern of poor adherence, although it is recognised that it may be different to other real-life situations; for example, patients may use inhalers regularly for 2 weeks and stop for the next 2 weeks. In this case, none of the ICSs studied would maintain protection during the weeks off treatment. The results presented here are based on an assumption that the medication doses are taken as intended with good inhaler technique, whereas in real life inhaler errors are common [64]. Furthermore, our simulation of infrequent as needed use is based on randomly assigned usage, rather than symptom-driven usage. However, in mitigation of this approach, many patients do not take their as-needed doses appropriately, since many patients are symptom under-perceivers [53]. Future work is required to validate and corroborate the current findings in actual clinical studies.

\section{CONCLUSIONS}

In conclusion, using a novel PK/PD model, these data show that ICS, at doses 
recommended for mild asthma can achieve good bronchoprotective efficacy when dosed regularly and with high adherence. For clinical scenarios that reflect poor adherence or infrequent dosing regimens of 3-4 times per week (as-needed), longer-acting ICS molecules (FF and to some extent FP) achieve better efficacy and overall benefit-risk ratios compared with shorter duration of action molecules (BUD), due to prolonged duration of airway GR occupancy. For patients identified as most at risk of poor adherence, a longer-acting ICS (FF and to some extent FP) would be more likely to maintain efficacy compared to an as-needed dosing regimen with BUD/formoterol. These data support regular daily maintenance dosing with ICS in patients with mild persistent asthma, reinforce the importance of encouraging better adherence with regular daily maintenance dosing regimens to ensure sustained levels of bronchoprotective efficacy and highlight the potential risks of under-treatment with ICS.

\section{ACKNOWLEDGEMENTS}

Dave Singh is supported by the National Institute for Health Research (NIHR) Manchester Biomedical Research Centre (BRC).

Funding. This study was funded by GlaxoSmithKline (GSK study number 214842). GSK-affiliated authors had a role in study design, data analysis, data interpretation, and writing of the report and GSK funded the journal's Rapid Service and Open Access fees.

Editorial Assistance. Editorial support was provided by Kate Hollingworth of Continuous Improvement Ltd and funded by GSK.

Authorship. All named authors meet the International Committee of Medical Journal Editors (ICMJE) criteria for authorship for this article, take responsibility for the integrity of the work as a whole, and have given their approval for this version to be published.
Author Contributions. Substantial contributions to study concept and design: PDY, SF, BA, ZL, DS. Data acquisition: PDY. Data analysis and interpretation: PDY, SF, ZL, BA, DS, AC. All authors have revised the work critically for important intellectual content and have provided final approval of the version to be published. Authors give their agreement to be accountable for all aspects of the work in ensuring that questions related to the accuracy or integrity of any part of the work are appropriately investigated and resolved.

Disclosures. Peter Daley-Yates, Bhumika Aggarwal, Zrinka Lulic and Sourabh Fulmali are employees of GlaxoSmithKline and hold GlaxoSmithKline shares. Alvaro A. Cruz has received a research grant from GlaxoSmithKline, and personal fees from Abdi Ibrahim, Boehringer Ingelheim, Chiesi, Eurofarma, INAF-Brazil, Mantecorp, Mylan and Novartis. Dave Singh has received personal fees from Aerogen, AstraZeneca, Boehringer Ingelheim, Chiesi, Cipla, Genentech, GlaxoSmithKline, Glenmark, Gossamerbio, Menarini, Novartis, Pfizer, Pulmatrix, Teva, Theravance, and Verona.

Compliance with Ethics Guidelines. This article is not based on any new studies with human participants or animals performed by any of the authors. The study data used in this study was derived from completed clinical trial (Protocol study 203,162; NCT02991859) [40]. The original study was approved by local ethics committees for the participating institutions (Ethikkommission des Landes Berlin, Berlin, Germany [reference number 17/0432-EK 10], and North West-GM South, NHS Health Research Authority, Manchester, UK [reference number 16/NW/0781]). The trial was conducted in accordance with Good Clinical Practice guidelines and the provisions of the Declaration of Helsinki. Written informed consent was obtained from each participant prior to any study-related procedures.

Data Availability. The datasets generated during and/or analysed during the current 
study are available from www. clinicalstudydatarequest.com.

Open Access. This article is licensed under a Creative Commons Attribution-NonCommercial 4.0 International License, which permits any non-commercial use, sharing, adaptation, distribution and reproduction in any medium or format, as long as you give appropriate credit to the original author(s) and the source, provide a link to the Creative Commons licence, and indicate if changes were made. The images or other third party material in this article are included in the article's Creative Commons licence, unless indicated otherwise in a credit line to the material. If material is not included in the article's Creative Commons licence and your intended use is not permitted by statutory regulation or exceeds the permitted use, you will need to obtain permission directly from the copyright holder. To view a copy of this licence, visit http:// creativecommons.org/licenses/by-nc/4.0/.

\section{REFERENCES}

1. Global Initiative for Asthma. Global strategy for asthma management and prevention. Global Initiative for Asthma (GINA), 2021. https://ginasthma. org/gina-reports/.

2. The British Thoracic Society. BTS/SIGN British guideline on the management of asthma, 2019. https://www.brit-thoracic.org.uk/standards-of-care/ guidelines/btssign-british-guideline-on-themanagement-of-asthma/.

3. Busse WW, Pedersen S, Pauwels RA, START Investigators Group, et al. The inhaled steroid treatment as regular therapy in early asthma (START) study 5-year follow-up: effectiveness of early intervention with budesonide in mild persistent asthma. J Allergy Clin Immunol. 2008;121(5):1167-74.

4. O'Byrne PM, Pedersen S, Lamm CJ, Tan WC, Busse WW, START Investigators Group. Severe exacerbations and decline in lung function in asthma. Am J Respir Crit Care Med. 2009;179(1):19-24.

5. Suissa S, Ernst P, Benayoun S, Baltzan M, Cai B. Low-dose inhaled corticosteroids and the prevention of death from asthma. N Engl J Med. 2000;343: 332-6.
6. O'Byrne P, Fabbri LM, Pavord ID, Papi A, Petruzzelli S, Lange P. Asthma progression and mortality: the role of inhaled corticosteroids. Eur Respir J. 2019;18(54):1900491.

7. Cerveri I, Locatelli F, Zoia MC, Corsico A, Accordini $\mathrm{S}$, de Marco R. International variations in asthma treatment compliance: the results of the European Community Respiratory Health Survey (ECRHS). Eur Respir J. 1999;14:288-94.

8. Bender B, Wamboldt FS, O'Connor SL, et al. Measurement of children's asthma medication adherence by self report, mother report, canister weight, and Doser CT. Ann Allergy Asthma Immunol. 2000;85:416-21.

9. Mäkelä MJ, Backer V, Hedegaard M, Larsson K. Adherence to inhaled therapies, health outcomes and costs in patients with asthma and COPD. Respir Med. 2013;107:1481-90.

10. Bårnes $\mathrm{CB}$, Ulrik $\mathrm{CS}$. Asthma and adherence to inhaled corticosteroids: current status and future perspectives. Respir Care. 2015;60:455-68.

11. Price $D$, Fletcher $M$, van der Molen T. Asthma control and management in 8,000 European patients: the REcognise Asthma and LInk to Symptoms and Experience (REALISE) survey. NPJ Prim Care Respir Med. 2014;24:14009.

12. Eakin MN, Rand CS. Improving patient adherence with asthma self-management practices: what works? Ann Allergy Asthma Immunol. 2012;109: $90-2$.

13. Mulgirigama A, Barnes N, Fletcher M, Pedersen S, Pizzichini E, Tsiligianni I. A review of the burden and management of mild asthma in adults-implications for clinical practice. Respir Med. 2019;152:97-104.

14. O'Byrne PM, FitzGerald JM, Bateman ED, et al. Inhaled combined budesonide-formoterol as needed in mild asthma. N Engl J Med. 2018;378(20): 1865-76.

15. Bateman ED, Reddel HK, O'Byrne PM, et al. AsNeeded budesonide-formoterol versus maintenance budesonide in mild asthma. $\mathrm{N}$ Engl J Med. 2018;378(20):1877-87.

16. Beasley R, Holliday M, Reddel HK, et al. Controlled trial of budesonide-formoterol as needed for mild asthma. N Engl J Med. 2019;380:2020-30.

17. Expert Panel Working Group of the National Heart, Lung, and Blood Institute (NHLBI) administered and coordinated National Asthma Education and Prevention Program Coordinating Committee (NAEPPCC), Cloutier MM, Baptist AP, Blake KV, 
et al. Focused updates to the asthma management guidelines: a report from the national asthma education and prevention program coordinating committee expert panel working group. J Allergy Clin Immunol. 2020;2020(146):1217-70.

18. Yang CL, Hicks EA, Mitchell P, et al. Canadian thoracic society guideline-a focused update on the management of very mild and mild asthma. Can J Respir Crit Care Sleep Med. 2021. https://doi.org/ 10.1080/24745332.2021.1877043.

19. Nakamura Y, Tamaoki J, Nagase H, et al. Japanese Society of Allergology. Japanese guidelines for adult asthma 2020. Allergol Int. 2020;69:519-48.

20. McGivern DV, Ward M, Macfarlane JT, Roderick Smith WH. Failure of once daily inhaled corticosteroid treatment to control chronic asthma. Thorax. 1984;39(12):933-4.

21. Munch EP, Laursen LC, Dirksen A, Weeke ER, Weeke B. Dose frequency in the treatment of asthmatics with inhaled topical steroids Comparison between a twice daily and a once daily dosing regimen. Eur J Respir Dis. 1985;67(4):254-60.

22. Crompton G. A brief history of inhaled asthma therapy over the last fifty years. Prim Care Respir J. 2006;15:326-31.

23. Boulet LP, Cowie RL, Negro RD, et al. Comparison of once-with twice-daily dosing of fluticasone propionate in mild and moderate asthma. Can Respir J. 2000;7:239-47.

24. Masoli M, Weatherall M, Beasley R. Fluticasone given once versus twice a day: meta-analysis. Respirology. 2005;10(2):183-8.

25. Daley-Yates PT. Inhaled corticosteroids: potency, dose equivalence and therapeutic index. Br J Clin Pharmacol. 2015;80(3):372-80.

26. Woodcock A, Bateman ED, Busse WW, et al. Efficacy in asthma of once-daily treatment with fluticasone furoate: a randomized, placebo-controlled trial. Respir Res. 2011;12:132.

27. Bardsley G, Daley-Yates P, Baines A, et al. Anti-inflammatory duration of action of fluticasone furoate/vilanterol trifenatate in asthma: a cross-over randomised controlled trial. Respir Res. 2018;19: 133.

28. Daley-Yates PT, Noushin B, Bharath K, et al. Dose responses for topical efficacy and systemic activity, dose equivalence and relative therapeutic index for fluticasone furoate (FF), fluticasone propionate (FP) and budesonide (BUD) in asthmatic subjects. Eur Respir J. 2019;54(suppl 63):2106.
29. Daley-Yates PT. Inhaled corticosteroids dose regimens: therapeutic relevance of lipophilicity, solubility, dissolution and absorption from the lung. Am J Respir Crit Care Med. 2019;199:A3331.

30. Daley-Yates PT. Pharmacological basis of inhaled corticosteroid dose equivalence and duration of action. Thorax. 2019;74(Suppl 2):A215-6.

31. Park G-M, Han HW, Kim JY, et al. Association of symptom control with changes in lung function, bronchial hyperresponsiveness, and exhaled nitric oxide after inhaled corticosteroid treatment in children with asthma. Allergol Int. 2016;65(4): 439-43.

32. Joos GF, O'Connor B, Anderson SD, et al. ERS Task Force. Indirect airway challenges. Eur Respir J. 2003;21:1050-68.

33. Sont JK, Willems LN, Bel EH, van Krieken JH, Vandenbroucke JP, Sterk PJ. Clinical control and histopathologic outcome of asthma when using airway hyperresponsiveness as an additional guide to long-term treatment. The AMPUL Study Group. Am J Respir Crit Care Med. 1999;159(4 Pt 1): 1043-51.

34. Sont JK, Han J, van Krieken JM, et al. Relationship between the inflammatory infiltrate in bronchial biopsy specimens and clinical severity of asthma in patients treated with inhaled steroids. Thorax. 1996;51:496-502.

35. Boulet LP. Asymptomatic airway hyperresponsiveness: a curiosity or an opportunity to prevent asthma? Am J Respir Crit Care Med. 2003;167: 371-8.

36. Woolcock AJ. What are the important questions in the treatment of asthma? Clin Exp Allergy Rev. $2001 ; 1: 62-4$.

37. Domingo C, Rello J, Sogo A. As-needed ICS-LABA in mild asthma: what does the evidence say? Drugs. 2019;79(16):1729-37.

38. Muneswarao J, Hassali MA, Ibrahim B, Saini B, Ali $\mathrm{IAH}$, Verma AK. It is time to change the way we manage mild asthma: an update in GINA 2019. Respir Res. 2019;20:183.

39. Rajan S, Gogtay NJ, Konwar M, Thatte UM. The global initiative for asthma guidelines (2019): change in the recommendation for the management of mild asthma based on the SYGMA-2 triala critical appraisal. Lung India. 2020;37:169-73.

40. Daley-Yates P, Brealey N, Thomas S, et al. Therapeutic index of inhaled corticosteroids in asthma: a dose-response comparison on airway 
hyperresponsiveness and adrenal axis suppression. Br J Clin Pharmacol. 2021;87:483-93.

41. Faassen F, Kelder J, Lenders J, Onderwater R, Vromans H. Physicochemical properties and transport of steroids across Caco-2 Cells. Pharm Res. 2003;20: 2.

42. Biggadike K, Bledsoe R, Hassell A, Högger P, Shewchuk L, Valotis A. Fluticasone furoate* (ff)-interactions with the glucocorticoid receptor *usan approved name. Ann Allergy Asthma Immunol. 2007;98(Suppl 1):A91-2.

43. Biggadike K, Bledsoe RK, Hassell AM, Kirk BE, McLay IM, Shewchuk LM, Stewart EL. X-ray crystal structure of the novel enhanced-affinity glucocorticoid agonist fluticasone furoate in the glucocorticoid receptor-ligand binding domain. J Med Chem. 2008;51(12):3349-52.

44. Ketchell RI, Jensen MW, Lumley P, Wright AM, Allenby MI, O'connor BJ. Rapid effect of inhaled fluticasone propionate on airway responsiveness to adenosine $5^{\prime}$-monophosphate in mild asthma. J Allergy Clin Immunol. 2002;110(4):603-6.

45. Luijk B, Kempsford RD, Wright AM, Zanen P, Lammers JW. Duration of effect of single-dose inhaled fluticasone propionate on AMP-induced bronchoconstriction. Eur Respir J. 2004;23(4): 559-64.

46. Phillips K, Oborne J, Harrison TW. Tattersfield AE Use of sequential quadrupling dose regimens to study efficacy of inhaled corticosteroids in asthma. Thorax. 2004;59(1):21-5.

47. GlaxoSmithKline. GSK Clinical Study Register. Study SIG103337 Clinical Pharmacology Study Report. https://s3.amazonaws.com/ctr-gsk-7381/ SIG103337/bd9b54da-4de9-4153-8a29.

881304d0982a/f82610a1-5ed2-42c1-86d3169fc32c2a86/gsk-sig103337-clinical-study-reportredact-v1.pdf. Accessed 23 Jul 2021.

48. Fardon TC, Fardon EJ, Hodge MR, Lipworth BJ. Comparative cutoff points for adenosine monophosphate and methacholine challenge testing. Ann Allergy Asthma Immunol. 2004;93(4): $365-72$.

49. Lötvall J, Inman M, O'Byrne P. Measurement of airway hyperresponsiveness: new considerations. Thorax. 1998;53:419-24.

50. Gibbons DC, Aggarwal B, Fairburn-Beech J, et al. Treatment patterns among non-active users of maintenance asthma medication in the United Kingdom: a retrospective cohort study in the Clinical Practice Research Datalink. J Asthma. 2021;58(6):793-804.
51. Hardy J, Baggott C, Fingleton J, et al. Budesonideformoterol reliever therapy versus maintenance budesonide plus terbutaline reliever therapy in adults with mild to moderate asthma (PRACTICAL): a 52-week, open-label, multicentre, superiority, randomised controlled trial. Lancet. 2019;394: 919-28.

52. Boushey HA, Sorkness CA, King TS, et al. National Heart, Lung, and Blood Institute's Asthma Clinical Research Network. Daily versus as-needed corticosteroids for mild persistent asthma. N Engl J Med. 2005;352:1519-28.

53. Barnes PJ, Szefler SJ, Reddel HK, Chipps BE. Symptoms and perception of airway obstruction in asthmatic patients: clinical implications for use of reliever medications. J Allergy Clin Immunol. 2019;144:1180-6.

54. Masoli M, Holt S, Weatherall M, Beasley R. Doseresponse relationship of inhaled budesonide in adult asthma: a meta-analysis. Eur Respir J. 2004;23: 552-8.

55. Holt S, Suder A, Weatherall M, Cheng S, Shirtcliffe $\mathrm{P}$, Beasley R. Dose-response relation of inhaled fluticasone propionate in adolescents and adults with asthma: meta-analysis. BMJ. 2001;323(7307):253-6.

56. Kokturk N, Mullaoglu S, Ozyilmaz E, Turktas H. The effect of low-dose inhaled budesonide on PC20 AMP levels in patients with mild asthma: a 3-month follow-up study. J Asthma. 2009;46: 259-64.

57. Cockcroft D, Davis B. Direct and indirect challenges in the clinical assessment of asthma. Ann Allergy Asthma Immunol. 2009;103:363-70.

58. Reddel HK, Taylor DR, Bateman ED, et al. American Thoracic Society/European Respiratory Society Task Force on Asthma Control and Exacerbations. An official American Thoracic Society/European Respiratory Society statement: asthma control and exacerbations: standardizing endpoints for clinical asthma trials and clinical practice. Am J Respir Crit Care Med. 2009;180:59-99.

59. van den Berge M, Kerstjens HA, de Reus DM, Koëter GH, Kauffman HF, Postma DS. Provocation with adenosine 5'-monophosphate, but not methacholine, induces sputum eosinophilia. Clin Exp Allergy. 2004;34:71-6.

60. De Meer G, Heederik D, Postma DS. Bronchial responsiveness to adenosine 5'-monophosphate (AMP) and methacholine differ in their relationship with airway allergy and baseline $\mathrm{FEV}_{1}$. Am J Respir Crit Care Med. 2002;165:327-31. 
61. Prieto L, Bruno L, Gutierrez V, et al. Airway responsiveness to adenosine 5'-monophosphate and exhaled nitric oxide measurements. Chest. 2003;124:1325-33.

62. Shao J, Talton J, Wang Y, Winner L, Hochhaus G. Quantitative assessment of pulmonary targeting of inhaled corticosteroids using ex vivo receptor binding studies. AAPS J. 2020;22:39.
63. Aziz I, Wilson AM, Lipworth BJ. Effects of oncedaily formoterol and budesonide given alone or in combination on surrogate inflammatory markers in asthmatic adults. Chest. 2000;118:1049-58.

64. Inhaler Error Steering Committee, Price D, BosnicAnticevich S, Briggs A, et al. Inhaler competence in asthma: common errors, barriers to use and recommended solutions. Respir Med. 2013;107:37-46. 